\title{
O Sistema Eleitoral de Lista Aberta no Brasil*
}

\author{
Jairo Nicolau
}

\begin{abstract}
T a resenha que escreveu a respeito do "estado da arte" dos estudos 1 sobre sistemas eleitorais, Matthew Shugart (2005) enfatizou o quanto se avançou nos últimos anos no conhecimento do impacto do sistema eleitoral sobre o sistema partidário. Em contraste, a pesquisa sobre como os sistemas eleitorais afetam a organização dos partidos e a relação dos deputados com suas bases eleitorais ainda necessita de estudos mais sistemáticos. Segundo Shugart: "o estudo da dimensão intrapartidária tem sido inibido por caracterizações nebulosas das variáveis dependentes, pela falta de dados, e o pior, uma falta de um claro entendimento de como as regras funcionam nos vários países pesquisados" (idem:36, tradução do autor). Uma das evidências dessa fragilidade é o número limitado de estudos comparativos que analisam os efeitos do sistema eleitoral no comportamento dos eleitores (Norris, 2004).
\end{abstract}

Atualmente, o conhecimento sobre a influência dos sistemas eleitorais no comportamento dos eleitores e da elite parlamentar é fruto, sobretudo, de generalizações feitas a partir de estudos de caso (Bogdanor, 1985; Gallaguer, 2005) e de tipologias de corte dedutivo (Carey e Shugart, 1995). Pesquisas comparativas permitiram um avanço do co-

*Este artigo foi escrito graças ao apoio recebido do Conselho Nacional de Desenvolvimento Científico e Tecnológico - CNPq e do Centre for Brazilian Studies - Oxford University.

DADOS - Revista de Ciências Sociais, Rio de Janeiro, Vol. 49, n-4, 2006, pp. 689 a 720. 
nhecimento em relação aos efeitos do Single Non-Transferable Vote - SNTV, adotado no Japão até 1993 e em outros países asiáticos (Grofman et alii, 1999), e do Single Transferable Vote-STV, utilizado na Irlanda e em Malta (Bowler e Grofman, 2000). Mas os esforços comparativos sobre os efeitos dos diferentes modelos de representação proporcional de lista têm se concentrado praticamente na elaboração de tipologias (Katz, 1997; 2005; Shugart, 2005). Sabe-se muito pouco, por exemplo, sobre como a lista fechada ou os vários modelos de voto preferencial afetam o atendimento aos eleitores (constituency service), o comportamento legislativo e o voto dos eleitores (Karvonen, 2004). Mas nesse aspecto em particular, as pesquisas comparativas dependem de investigação mais sistemática a respeito das regras e das singularidades produzidas pelos estudos de caso.

A utilização do sistema de lista aberta no Brasil chama a atenção por uma série de razões. A primeira delas é a longevidade. Nenhum país do mundo utiliza a lista aberta há tantos anos. A segunda deriva da magnitude do eleitorado brasileiro, 115 milhões em 2002, em contraste com o de outros países que utilizam o mesmo modelo: Polônia, 29,4 milhões (2001); Peru, 14,9 milhões (2001); Chile, 8,1 milhões (2001); Finlândia, 4,1 milhões (1999) ${ }^{1}$; como veremos, o número de eleitores é particularmente importante para definir certos padrões de relação entre representados e representantes. A terceira razão está associada à combinação da lista aberta com outros atributos do sistema eleitoral: grandes distritos eleitorais, possibilidade de realização de coligações eleitorais, eleições simultâneas para outros cargos (presidente e governadores de estado e senadores) e distorção acentuada na representação dos estados na Câmara dos Deputados.

Apesar da sua importância, o sistema de lista aberta brasileiro tem recebido limitada atenção dos estudiosos. Nos últimos anos, poucos estudos (Mainwaring, 1991; Ames, 1995; Samuels, 1999) trataram especificamente do tema. Em que pese o impacto dos três trabalhos na comunidade de estudiosos sobre os sistemas eleitorais, eles concentraram-se em aspectos muito específicos do funcionamento do sistema eleitoral brasileiro. Mainwaring (1991) detém-se na descrição das regras e na comparação com outras experiências de países com voto preferencial (Itália, Chile e Finlândia), e apresenta limitadas evidências empíricas. O artigo de Ames (1995) só indiretamente discute a questão do sistema eleitoral; o estudo tem duas preocupações distintas: saber se os deputados eleitos em 1986 submeteram emendas orçamentárias 
para as municipalidades onde foram votados e avaliar o sucesso eleitoral dos deputados que concorreram em 1990². Samuels (1999) preocupa-se especificamente em mostrar como um partido, o $\mathrm{PT}^{*}$, conseguiu incentivar a reputação partidária em um sistema eleitoral centrado nos candidatos.

O objetivo deste artigo é fazer uma análise sistemática do funcionamento do sistema de lista aberta no Brasil, particularmente nas eleições para a Câmara dos Deputados. Inspirado pelo modelo proposto por Gallaguer e Mitchell (2005), começo descrevendo a história e o funcionamento do sistema de lista aberta em vigor no país. A seguir, avalio os possíveis efeitos deste sistema em três dimensões: partidos, eleitores e a relação dos deputados com as bases eleitorais. O texto termina discutindo um tema fundamental para a teoria democrática (ou pelo menos para uma de suas versões), que é a capacidade que o sistema representativo oferece para os eleitores punirem ou recompensarem os legisladores por intermédio do voto. Além de conectar o caso brasileiro com a moderna reflexão sobre os sistemas eleitorais, mobilizo evidências de três diferentes pesquisas feitas com deputados e eleitores, que trazem dados mais consistentes sobre diversos aspectos do sistema representativo brasileiro ${ }^{3}$.

\section{ORIGEM E FUNCIONAMENTO DA LISTA ABERTA NO BRASIL}

A primeira versão de representação proporcional adotada no Brasil em 1932 já previa o voto preferencial. A cédula podia conter um grande número de candidatos (tantos quantas fossem as cadeiras do estado na Câmara dos Deputados mais um), e o eleitor podia escolher candidatos de diferentes partidos e até mesmo nomes de candidatos não inscritos em nenhum partido - um modelo semelhante ao utilizado na Suíça atualmente. Mas o processo de apuração privilegiava o nome que encabeçava a lista de candidatos, já que o cálculo da distribuição das cadeiras entre os partidos só considerava esse voto; os outros nomes da lista só podiam disputar as cadeiras não alocadas na primeira distribuição (sobras). Este sistema foi utilizado nas eleições de 1933 e 1934, mas as críticas à complexidade da apuração (que chegou a demorar semanas em alguns estados) foi um forte estímulo para adoção, em 1935, de uma versão mais simples, na qual o eleitor passaria a votar em um único nome. Por conta da suspensão das eleições durante o governo auto-

\footnotetext{
* Ver lista de siglas dos partidos políticos com os respectivos significados ao final do artigo.
} 
ritário de Getúlio Vargas (1937-1945), a nova regra só entrou em vigor nas eleições de 1945 (Porto, 1989; Nicolau, 2002). É interessante observar que o Brasil adotou o sistema de lista aberta antes de outros dois países - a Finlândia (1955) e o Chile (1958) - que ficariam conhecidos por utilizar esta versão de representação proporcional (Raunio, 2005; Siaveles, 2005).

O sistema em vigor no Brasil oferece duas opções aos eleitores: votar em um nome ou em um partido. As cadeiras obtidas pelos partidos (ou coligações entre partidos) são ocupadas pelos candidatos mais votados de cada lista. É importante sublinhar que as coligações entre os partidos funcionam como uma única lista; ou seja, os mais votados da coligação, independentemente do partido ao qual pertençam, elegem-se. Diferentemente de outros países (Chile, Finlândia e Polônia) onde os eleitores têm que obrigatoriamente votar em um nome da lista para ter o seu voto contado para o partido, no Brasil os eleitores têm a opção de votar em um nome ou em um partido (legenda). O voto de legenda é contado apenas para distribuir as cadeiras entre os partidos, mas não tem nenhum efeito na distribuição das cadeiras entre os candidatos ${ }^{4}$.

Na história da lista aberta no Brasil, dois aspectos merecem destaque. O primeiro é a forma como os nomes dos candidatos foram apresentados aos eleitores. Diferentemente do que acontece em outros países que adotam o voto preferencial (Holanda, Bélgica, Dinamarca, Áustria e Finlândia, por exemplo), a cédula brasileira nunca apresentou uma lista completa de todos os candidatos. Nos três diferentes processos de votação empregados desde 1945 (a cédula impressa pelos partidos, a cédula oficial e a urna eletrônica), votar nas eleições para Câmara dos Deputados foi sempre escrever (ou digitar, após a introdução da urna eletrônica) o nome ou o número de um candidato sem qualquer menção aos outros componentes da lista. Tal fato, associado à escolha de outros cargos pelo sistema majoritário na mesma eleição, acabou contribuindo para reforçar nos eleitores a falsa impressão de que as eleições para a Câmara dos Deputados são feitas segundo uma regra majoritária em que todos os candidatos concorrem entre si.

Um segundo aspecto relevante refere-se ao processo de institucionalização do voto partidário (legenda). Nas eleições para a Câmara dos Deputados, realizadas entre 1945 e 1958, não havia cédula oficial. Em geral, elas eram impressas pelos partidos e distribuídas no dia das elei- 
ções pelos cabos eleitorais e também colocadas pelo presidente das mesas eleitorais no interior da cabine de votação. Neste período, votar significava comparecer aos locais de votação para colocar a cédula confeccionada pelos partidos em um envelope e, posteriormente, colocar este em uma urna. Os votos de legenda eram contabilizados apenas no processo de apuração, quando houvesse imprecisões de preenchimento mas ainda assim fosse possível identificar o partido no qual o eleitor havia votado ${ }^{5}$. A cédula oficial (impressa pela Justiça Eleitoral) começou a ser utilizada em 1962. Tal medida tornaria o processo de votação mais difícil, já que o eleitor passou a ter que escrever o nome (ou número) do candidato, e/ou a sigla do partido ou coligação pelo qual este concorria. Na realidade, ao apresentar um espaço específico para o eleitor votar em um partido, a cédula oficial introduziu de maneira mais formal o voto de legenda. Essas regras não foram alteradas nas eleições realizadas durante o Regime Militar - com exceção apenas de 1982, quando a cédula não trouxe espaço específico para o eleitor votar na legenda. Nas primeiras eleições após o Regime Militar (1986), a cédula manteve a antiga opção de votar em um nome e/ ou número de um candidato, mas inovou ao apresentar uma lista de todos os partidos, na qual o eleitor poderia marcar o de sua preferência. Com isso, a opção pelo voto exclusivo em um partido ficou mais clara. Em 1994 e 1998, a lista das siglas dos partidos foi retirada da cédula e, para votar na legenda, o eleitor teve que escrever o nome (ou o número) do partido preferido. Desde 1998, o eleitor vota na urna eletrônica ${ }^{6}$.

\section{A Seleção de Candidatos}

Na disputa para a Câmara dos Deputados, os partidos podem apresentar uma lista de candidatos de até uma vez e meia o número de cadeiras da circunscrição eleitoral; no caso de coligação entre partidos, esse número sobe para duas vezes. Nas circunscrições eleitorais que elegem até 20 representantes, um partido pode apresentar até o dobro de candidatos; ou até duas vezes e meia quando há coligação. Desde 1998, há uma quota de candidatos por gênero que o partido deve respeitar, introduzida com o objetivo de ampliar o número de mulheres representadas no Legislativo. As listas devem reservar o mínimo de $30 \%$ e o máximo de $70 \%$ para candidaturas de cada sexo. Apesar dessa determinação, o total de mulheres inscritas pelos partidos tem sido inferior ao estabelecido: apenas 10,3 \% em 1998 e 11,3\% em 2002. Em 1998, a exigência de quota mínima foi cumprida apenas pelo PCB, que lançou duas 
mulheres entre os seus cinco candidatos. Nenhum partido cumpriu a determinação em $2002^{7}$.

Um candidato não pode concorrer em listas de outros estados nem disputar simultaneamente outros cargos na mesma eleição. Para ser candidato a qualquer cargo, um cidadão deve estar filiado há pelo menos um ano a um determinado partido. Existe ainda uma exigência de vínculo territorial (domicílio eleitoral) a um determinado município (e conseqüentemente um determinado estado) também por pelo menos um ano; por exemplo, para ser candidato a deputado federal pelo Rio de Janeiro, um cidadão deve estar filiado a um partido no estado há pelo menos um ano. Existem ainda exigências de alfabetização (os analfabetos podem votar, mas não podem ser candidatos) e de idade mínima de 21 anos para ser candidato a deputado federal. Até 1998, a legislação garantia aos deputados com mandato (ou aos que o tivessem exercido durante a legislatura em curso) o registro da candidatura para o mesmo cargo pelo partido ao qual estivessem filiados (candidatura nata); ou seja, os responsáveis para escolher os candidatos do partido não tinham poder para excluir os parlamentares da lista. Em 2002, o Supremo Tribunal Federal julgou este privilégio inconstitucional, e ele deixou de vigorar nas eleições daquele $a o^{8}$.

A legislação partidária estabelece que a norma para escolha dos candidatos deve ser definida pelo regimento interno de cada partido. A única exigência é que façam uma convenção no âmbito estadual para formalizar a escolha dos candidatos; as convenções devem acontecer entre os dias 10 e 30 de junho do ano eleitoral, e a lista de candidatos deve ser registrada até o dia 5 de julho na Justiça Eleitoral. Os partidos podem coligar-se para a disputa das cadeiras de cada distrito eleitoral ${ }^{9}$. Entre 1986 e 1998, os diretórios estaduais dos partidos tinham autonomia para decidir sobre as coligações, sendo raros os casos de interferência das instâncias nacionais dos partidos nesta decisão. A legislação apenas vedava que os partidos celebrassem coligações diferentes para cargos majoritários e proporcionais. Por exemplo, os partidos A, B e C poderiam coligar-se para o governo do estado e concorrerem com diferentes combinações para a Câmara dos Deputados ( $\mathrm{ABC}$; $\mathrm{AB} C$; $\mathrm{BCA}$; $\mathrm{ACB} ; \mathrm{ABC}$ ); a proibição seria aliar-se ao partido $\mathrm{D}$ para um dos cargos em disputa. Em 2002, decisão do Tribunal Superior Eleitoral - TSE proibiu que os partidos que se coligaram nas eleições presidenciais celebrassem coligações diferentes no âmbito estadual. Assim, a coligação $\mathrm{ABC}$ pode assumir várias configurações em cada um dos estados, mas 
não pode incluir um partido da coligação presidencial DEF; curiosamente, um partido que não apresentou candidato a presidente pôde se coligar com qualquer partido nos estados.

Ainda conhecemos pouco sobre o processo pelo qual os partidos escolhem os seus candidatos, particularmente, nas eleições para a Câmara dos Deputados ${ }^{10}$. Não sabemos, por exemplo, se os partidos organizam comitês específicos para escolher os candidatos, ou se as principais lideranças estaduais envolvem-se diretamente nessa tarefa. Dois aspectos, contudo, devem ser salientados. O primeiro é que nenhum partido utiliza prévias internas com os filiados para a escolha dos nomes que comporão a lista, o segundo é que as convenções oficiais têm caráter meramente homologatório, já que os candidatos são escolhidos antes que elas aconteçam.

A quantidade e o perfil de candidatos que cada partido apresenta para deputado federal em cada circunscrição eleitoral dependem de uma série de fatores, tais como o seu tamanho, a possibilidade de fazer coligações e o número de cidadãos que pretendem se candidatar. Minha hipótese é que tanto a dimensão territorial como a diversidade social dos candidatos são fatores fundamentais para os organizadores da lista. Os responsáveis pela organização da lista procurariam levar em conta critérios geográficos, atraindo nomes de diversas regiões do estado e evitando superposições de candidatos da mesma área, e tenderiam a privilegiar nomes com prestígio junto a setores específicos do eleitorado: líderes sindicais, de corporações profissionais e empresariais; ativistas de movimentos sociais (mulheres, negros, moradores, ambientalistas); líderes religiosos; ou personalidades que tenham se destacado em algum ramo de atividade específico (radialistas, artistas, esportistas, intelectuais). Mas somente estudos detalhados sobre o perfil dos candidatos poderão confirmar a relevância desses dois fatores.

Um aspecto interessante refere-se ao número de candidatos que os partidos apresentam em cada estado. Como o total de cadeiras que o partido receberá é o resultado agregado da votação que cada candidato conquistará individualmente, é razoável supor que o partido terá interesse de ter o maior número possível de nomes na lista. Uma exceção acontece com os menores partidos, que, quando coligados com os maiores, tendem a privilegiar outra estratégia: apresentar um número reduzido de candidatos e concentrar os recursos de campanha nesses nomes. Apesar desse incentivo geral para apresentar muitos nomes, ne- 
nhum partido conseguiu preencher sozinho todas as vagas disponíveis nas três últimas eleições para a Câmara dos Deputados (1994, 1998 e $2002)^{11}$. O que precisa ser investigado mais detalhadamente é em que medida isto é fruto de uma escolha deliberada dos partidos ou decorre do fato de que um número relativamente reduzido de cidadãos ambiciona ser deputado federal.

\section{As Estratégias de Campanha Eleitoral ${ }^{12}$}

Um candidato a deputado federal tem grande autonomia para organizar sua campanha. É ele que, em geral, decide a agenda de eventos e como confeccionar e distribuir a propaganda eleitoral. A autonomia para gerir a campanha é reconhecida pela legislação em um aspecto fundamental: o financiamento. Os candidatos podem arrecadar, gastar e prestar contas diretamente à Justiça Eleitoral, sem necessidade de o partido avalizar os gastos ${ }^{13}$.

O tipo de campanha que um candidato faz depende, em larga medida, do seu perfil político e dos recursos de que dispõe. Praticamente todos os candidatos organizam atividades que permitem um contato direto com os eleitores em lugares públicos (comícios, panfletagens, visitas a áreas de concentração popular) ou em eventos privados (visitas ou reuniões com pequenos grupos). Nesses eventos, o candidato geralmente distribui material impresso com dados de sua biografia e oferece brindes (camisetas, bonés, calendários) aos eleitores ${ }^{14}$. Na cobertura que a imprensa faz das campanhas aparecem alguns casos de candidatos que oferecem aos eleitores recursos ou algum tipo de vantagem pessoal em troca do voto ${ }^{15}$. Devido ao grande número de candidatos que se apresentam e das diferentes estratégias utilizadas por cada um deles, é difícil mensurar o grau de permanência de práticas clientelistas nas eleições para a Câmara dos Deputados. Em 1999, foi aprovada a Lei no 9.840, proibindo que os candidatos doem, ofereçam, prometam ou entreguem ao eleitor vantagens em troca do voto. Os infratores, além de pagar uma multa, podem perder o registro da candidatura ou o mandato. Além do contato direto, os candidatos procuram difundir o seu nome (e número) em propagandas afixadas nas residências (placas e cartazes $)^{16}$.

Para a maioria dos candidatos, é fundamental arregimentar eleitores para apoiar diretamente a sua campanha. Os que têm mais recursos organizam uma rede de apoios nos menores municípios, ou em bairros 
nas grandes cidades. Em geral, as regiões escolhidas são aquelas em que o candidato já desenvolve algum tipo de atividade política - no caso dos candidatos com mandato, são as áreas prioritárias da atuação parlamentar. Essas redes podem contar com o apoio de vereadores, prefeitos, lideranças locais sem mandato e candidatos a outros cargos na mesma eleição (sobretudo, deputados estaduais). O apoio de lideranças municipais prevê compromissos de apoio em eleições locais futuras, ou são retribuições de apoios recebidos no passado. $\mathrm{O}$ candidato pode ainda contratar profissionais para exercer tarefas específicas, como distribuir panfletos, segurar faixas em lugares públicos, cuidar do comitê de campanha ou produzir material que será distribuído. Alguns candidatos conseguem ainda o apoio de militantes voluntários, uma prática mais comum nos partidos de esquerda.

Os candidatos têm direito a aparecer no Horário Gratuito de Propaganda Eleitoral - HGPE, veiculado no rádio e na televisão. A lei designa três dias da semana durante 45 dias para veiculação de propaganda dos candidatos a deputado federal. A propaganda vai ao ar duas vezes ao dia, em programas de 50 minutos. Como o horário eleitoral dura cerca de seis semanas, o tempo total para a aparição dos candidatos é de cerca de 900 minutos. Este tempo é distribuído proporcionalmente à representação dos partidos na Câmara dos Deputados, o que significa que os partidos maiores terão bem mais tempo para expor os seus candidatos do que os pequenos. Como os partidos maiores tendem a apresentar mais candidatos, o tempo de aparição de cada nome também acaba sendo limitado. Para dar um exemplo: nas eleições de 2002, em São Paulo, havia 724 candidatos na disputa - o que garantiu, em média, pouco mais de um minuto na televisão para cada um. Os partidos têm criado diferentes estratégias para lidar com o reduzido tempo do HGPE que eles têm disponível. Alguns asseguram mais tempo para determinados nomes, os puxadores de legenda; outros apresentam apenas as fotos e um breve currículo dos candidatos. Embora a maioria dos candidatos acredite na eficiência do HGPE como forma de comunicação, ainda sabemos pouco sobre até que ponto ele é determinante para o sucesso eleitoral. Um estudo pioneiro sobre a campanha dos deputados no HGPE em 1994 (Schmitt, Carneiro e Kuschnir, 1999) encontrou uma correlação razoável ( $r$ de Pearson $=0,5$ ) entre a votação dos candidatos a deputado federal e o tempo de aparição destes durante a campanha na televisão ${ }^{17}$. 


\section{EFEITOS}

\section{Efeitos sobre os Partidos}

Carey e Shugart (1995) escreveram o mais influente artigo a respeito dos possíveis efeitos dos sistemas eleitorais sobre a estratégia eleitoral dos candidatos. A preocupação central é saber se os sistemas eleitorais oferecem incentivos para que os candidatos ao Legislativo cultivem a reputação personalizada ou a partidária. A definição dos autores sobre a reputação personalizada é a seguinte: "se as perspectivas de sucesso eleitoral aumentam como resultado de ser pessoalmente bem conhecido e apreciado pelo eleitor, então a reputação pessoal importa. Quão mais isso importa, mais valorizada é a reputação pessoal" (idem:419, tradução do autor). A definição de reputação partidária é mais sucinta: "reputação partidária refere-se à informação que o rótulo partidário transmite para os eleitores em um dado distrito eleitoral" (ibidem, tradução do autor). Os autores montaram uma classificação que levou em conta três atributos: o controle partidário para selecionar os candidatos; se os candidatos são eleitos individualmente, independentemente dos colegas de partido; se o voto é único, intrapartidário, múltiplo ou partidário. A distinção entre sistemas uninominais (que elegem um representante por distrito) e plurinominais (que elegem mais de um representante por distrito) também foi considerada. A partir de escores atribuídos a cada um desses aspectos, os autores chegaram a 13 combinações. O procedimento utilizado é basicamente dedutivo, mobilizando exemplos diversos de países, localidades, e até das eleições da New York City School Boards para ilustrar cada combinação (idem:425, tradução do autor). A classificação proposta mostrou-se particularmente limitada para a análise das variantes de representação proporcional com voto preferencial. Por exemplo, os sistemas de lista aberta do Chile, da Polônia, da Finlândia e do Brasil, apesar de características semelhantes, ficaram em posições muito distantes na escala. A classificação também negligenciou as diferentes regras utilizadas no sistema de lista flexível ${ }^{18}$.

Independentemente das limitações da tipologia proposta por Carey e Shugart (1995), os estudiosos dos sistemas eleitorais em geral concordam que a lista aberta tende a estimular as campanhas centradas no candidato. Como os candidatos têm que obter votos individuais, é natural que reforcem seus atributos (reputação pessoal) para se distinguir dos colegas de partido, ou dos atributos que são comuns a todos os membros do partido (reputação partidária). Os estudos sobre os dois 
países que utilizam a lista aberta por longo período (Finlândia e Chile) mostram uma predominância de campanhas centradas nos candidatos. Na Finlândia, os candidatos individuais são os responsáveis por arrecadar fundos e distribuir material de campanha. Embora exista publicidade partidária, os candidatos investem recursos expressivos de propaganda individual na imprensa ou na mídia eletrônica, enfatizando suas qualidades pessoais (Raunio, 2005). No Chile, durante o período 1958-1973, ainda que os partidos tivessem um processo centralizado de escolha de candidatos, estes cultivavam o voto individual oferecendo benefícios particularistas para os eleitores (Siaveles, 2005).

Há poucas pesquisas empíricas acerca dos efeitos da lista aberta sobre os partidos no Brasil (Samuels, 1999; Carvalho, 2000) ${ }^{19}$. A melhor evidência que existe reforça a idéia de campanhas centradas no candidato. Carvalho (idem) fez uma detalhada pesquisa de opinião com os deputados federais em 1999. Respondendo a diversas questões, eles reconheceram a grande autonomia de suas campanhas e a reduzida capacidade que os partidos teriam para intervir no processo eleitoral. Uma das questões pedia aos deputados que assinalassem em uma escala (de zero a 100) o peso de seus esforços pessoais e, em outra, o peso do partido. A média final do peso dos esforços pessoais foi 75. A média para os esforços pessoais dos principais partidos é a seguinte: PTB (94); PFL (83); PPB (80); PSDB (79); PMDB (74); PDT (70); PT (52); PCdoB (40)20. Mas reconhecer que as campanhas são centralizadas nos candidatos não significa dizer que elas sejam somente centralizadas nos candidatos. Os partidos utilizam freqüentemente os recursos de campanha (sobretudo, o HGPE) para divulgar sua propaganda partidária; é comum, por exemplo, que os dirigentes e os candidatos a cargos majoritários solicitem aos eleitores que votem na legenda na disputa para cargos proporcionais (Samuels, 1999). Mas como fica claro pelos dados, à exceção dos deputados do PT e do PCdoB, essa influência é considerada marginal.

Até que ponto o efeito do sistema eleitoral tem um impacto na configuração organizacional de um partido? Em que medida a maior ou menor institucionalização dos partidos está associada a determinados sistemas eleitorais? Além do sistema eleitoral, outras dimensões do sistema político afetam os partidos, por exemplo: o sistema de governo (presidencialismo, parlamentarismo, semipresidencialismo); a estrutura vertical de poder (federalismo, unitarismo); o processo decisório no interior do Legislativo; a legislação partidária; as diferentes questões que dividem a elite política; iniciativas organizacionais específicas de cada partido. $\mathrm{Na}$ realidade, os estudos comparativos deram contribuições muito limita- 
das para a compreensão de quais fatores afetam a natureza da organização partidária de cada país, e sobretudo para a avaliação do impacto específico produzido pelos sistemas eleitorais (Gallaguer, 2005). A variedade de tipos de partidos no interior de um mesmo país mostra que os efeitos dos sistemas eleitorais devem ser matizados (Gunther e Diamond, 2003). No Brasil, por exemplo, mesmo com um sistema altamente centrado no candidato, um partido (PT) conseguiu desenvolver mecanismos de reforço da reputação partidária (Samuels, 1999; Leal, 2005). A simples escolha de certas regras internas, tais como o incentivo de atividades partidárias entre as eleições, a profissionalização de um grande número de dirigentes, a punição para os deputados que não votam segundo a deliberação da bancada e a obrigatoriedade de contribuição mensal colaborou para que o PT conseguisse criar uma estrutura organizacional diferente da dos demais partidos brasileiros.

Além do incentivo para que as campanhas sejam centradas no candidato, a lista aberta afeta os partidos por estimular a competição entre os membros de uma mesma legenda. Como a alocação intralista é feita pelo sistema majoritário, os candidatos têm como principais adversários os colegas da própria lista e não de outros partidos. Muitas vezes, esses efeitos são contrastados com aqueles produzidos pela lista fechada, na qual a competição seria concentrada na disputa entre os partidos (Mainwaring, 1991; Nicolau, 1996; 2004). No Brasil, a competição entre os candidatos de uma mesma lista tende a ser agravada pelo alto grau de incerteza que caracteriza uma eleição para deputado federal, com um número de candidatos de cada lista, em geral, muito superior ao potencial eleitoral do partido, e pela reduzida informação que os candidatos têm sobre o potencial eleitoral do partido e de seus colegas de lista ${ }^{21}$.

Ainda que em termos lógicos seja razoável esperar um incentivo maior para a disputa entre os candidatos no sistema de lista aberta do que no sistema de lista fechada, não é fácil avaliar empiricamente a competitividade entre candidatos. Um caminho possível é observar como o sistema afeta os parlamentares que pretendem a reeleição. Nesse caso, é interessante saber se um candidato não-reeleito foi derrotado por conta do seu desempenho ou do partido. Katz (1986) examinou os efeitos da disputa intrapartidária em 13 países. Os dados mostraram uma grande variação: em alguns países o contingente de parlamentares derrotados por conta do desempenho do partido é superior (Bélgica, Dinamarca, Irlanda, Holanda, Noruega, Suíça e Estados Unidos), en- 
quanto em outros a derrota por outros nomes da lista é maior (Finlândia, Grécia, Itália, Japão, Luxemburgo e Malta). Mas, no total, o número de derrotados por outros colegas da lista é relativamente baixo, variando entre 17\% na Grécia e 7,8\% na Itália.

Segundo Katz (idem) os candidatos à reeleição podem perder o mandato por duas razões: ou por falha do partido, ou por falha do candidato. A derrota de um candidato é atribuída ao partido quando não há nome novo na lista final dos eleitos por aquele partido (ou seja, os parlamentares da legislatura passada reelegeram-se), ou quando o partido pelo qual ele concorreu não elegeu ninguém. A falha é do candidato quando o partido elege algum nome novo e ele fica de fora. O mesmo critério foi seguido para analisar o desempenho dos deputados que tentaram a reeleição em três eleições para a Câmara dos Deputados (1994, 1998 e 2002) no Brasil ${ }^{22}$. Os resultados são apresentados na Tabela 1 . O número total de deputados que se elegeram em uma eleição e se recandidataram na eleição seguinte é de 1.094. Desses, 743 (68\%) reelegeram-se, $241(22 \%)$ foram derrotados por falha do candidato, e $110(10 \%)$ foram derrotados por falha do partido ${ }^{23}$. Ou seja, o número de deputados federais que não se reelegeram por terem sido derrotados por outros membros da lista é mais do que o dobro dos derrotados por conta do desempenho do partido. Esse alto número de derrotados na lista (maior do que qualquer outro país com voto preferencial) pode ser interpretado como um forte indício da intensa disputa entre os candidatos de um mesmo partido.

\section{Efeitos sobre os Eleitores}

Os estudos sobre comportamento eleitoral têm se dedicado a investigar as motivações que conduzem o eleitor a votar em um determinado candidato. Um dos temas fundamentais é a influência dos atributos do candidato (voto personalizado) na decisão do eleitor. Na definição clássica apresentada por Cain, Farejohn e Fiorina (1987:9):

"O voto personalizado refere-se à porção do apoio eleitoral de um candidato que se origina em suas qualidades pessoais, qualificações, atividades e desempenho. A parte do voto que não é personalizada inclui apoio a um candidato baseado na sua filiação partidária, determinadas características do eleitor como classe, religião e etnia, reações às condições nacionais, tais como o estado da economia, e avaliação centrada no desempenho do partido que está no governo" (tradução do autor). 
Tabela 1

Número de Candidatos e Percentual de Reeleitos e Não-Reeleitos Câmara dos Deputados, Brasil, Eleições de 1994, 1998 e 2002

\begin{tabular}{l|c|c|c|c}
\hline Partidos & $\begin{array}{c}\text { Número de Deputados } \\
\text { que se Recandidataram }\end{array}$ & $\begin{array}{c}\% \\
\text { Reeleitos }\end{array}$ & $\begin{array}{c}\% \\
\text { Derrotas } \\
\text { Intralista }\end{array}$ & $\begin{array}{c}\% \\
\text { Derrotas Partido }\end{array}$ \\
\hline PFL & 221 & 74 & 19 & 7 \\
PMDB & 194 & 66 & 29 & 5 \\
PSDB & 160 & 69 & 25 & 6 \\
PPB & 147 & 71 & 20 & 8 \\
PT & 89 & 82 & 17 & 1 \\
PTB & 65 & 44 & 19 & 15 \\
PDT & 57 & 71 & 87 & 19 \\
PL & 38 & 62 & 18 & 11 \\
PP & 34 & 50 & 33 & 20 \\
PSB & 30 & 80 & 0 & 17 \\
PCdoB & 20 & 38 & 22 & 20 \\
PPS & 13 & 38 & 12 & 38 \\
Outros & 26 & $\mathbf{6 8}$ & $\mathbf{2 2}$ & $\mathbf{1 0}$ \\
\hline Total & $\mathbf{1 . 0 9 4}$ & &
\end{tabular}

Fonte dos dados brutos: Tribunal Superior Eleitoral.

Apesar de não esgotar todas as possibilidades de escolhas dos eleitores, a distinção entre o voto partidário e o personalizado passou a ser a dominante nos estudos sobre os efeitos dos sistemas eleitorais nos eleitores (Dalton e Wattemberg, 2000; Norris, 2004). No Brasil, a possibilidade que os eleitores têm de escolher entre votar em um partido ou em um candidato sugere que a decisão do eleitor possa ser analisada, respectivamente, como expressão de voto partidário ou voto personalizado (Samuels, 1999). A Tabela 2 apresenta o percentual de voto de legenda obtido pelos principais partidos nas quatro últimas eleições para a Câmara dos Deputados. Os números revelam uma intensa variação quando os partidos e o ano de cada eleição são analisados. Particularmente interessante é o desempenho do PT, partido que sempre se beneficiou com altos contingentes de voto de legenda: o percentual de votos de legenda vem caindo sistematicamente; passou de 43\% em 1990 para 15\% em 2002.

Muitas razões podem ser mobilizadas para tentar explicar a variação apresentada na Tabela 2. Em primeiro lugar, é interessante assinalar a mudança no formato da cédula, que apresentou graus diferenciados 
Tabela 2

Percentual de Voto de Legenda Obtido pelos Principais Partidos Eleições para a Câmara dos Deputados, 1986-2002

\begin{tabular}{l|c|c|c|c}
\hline & $\mathbf{1 9 9 0}$ & $\mathbf{1 9 9 4}$ & $\mathbf{1 9 9 8}$ & $\mathbf{2 0 0 2}$ \\
\hline PT & 43 & 33 & 26 & 15 \\
PSDB & 10 & 11 & 20 & 9 \\
PMDB & 16 & 4 & 9 & 6 \\
PFL & 7 & 2 & 6 & 6 \\
PDT & 24 & 5 & 18 & 18 \\
PPB & 28 & 2 & 9 & 8 \\
PTB & 11 & 2 & 9 & 7 \\
PSB & 9 & 2 & 8 & 9 \\
PPS & 23 & 3 & 28 & 11 \\
PCdoB & 18 & 2 & 8 & 4 \\
PL & 10 & 2 & 10 & 6 \\
Brasil & $\mathbf{1 8}$ & $\mathbf{8}$ & $\mathbf{1 4}$ & $\mathbf{1 0}$ \\
\hline
\end{tabular}

Fonte dos dados brutos: Tribunal Superior Eleitoral.

de dificuldade para o eleitor expressar sua preferência por um partido: em 1986 e 1990, a cédula trazia uma lista com todas as siglas dos partidos ${ }^{24}$; em 1994 e 1998 (para os eleitores que não votaram na urna eletrônica), a escolha pelo voto de legenda ficou mais difícil, pois a cédula não trazia mais a lista de legendas, e o eleitor passou a ter que escrever a sigla ou o número do partido; com a urna eletrônica (1998 e 2002), o eleitor passou a ter que digitar o número do partido. Em segundo lugar, a variação do voto de legenda reflete também diferentes estratégias utilizadas na campanha; por exemplo, lideranças e candidatos a cargos majoritários pedem explicitamente para que os eleitores votem na legenda no HGPE. Por fim, o voto de legenda expressa também os vínculos de longo prazo que os eleitores têm com os partidos (identificação partidária), que também variam no tempo, segundo os partidos e as regiões do país.

Os dados agregados são, porém, uma fonte limitada para se fazer inferências seguras sobre as motivações do eleitor. Não é possível interpretar o voto em candidatos como expressão pura e simples do voto personalizado porque muitos eleitores com vínculos mais permanentes com os partidos preferem, muitas vezes, votar em um nome específico da lista. Por outro lado, também não é possível dizer que o voto de legen- 
da seja expressão exclusiva de identificação partidária de longo prazo (voto partidário), pois ele muitas vezes reflete escolhas de curto prazo motivadas pela campanha eleitoral. Por isso, o caminho mais seguro para avaliar o impacto dos partidos sobre a decisão dos eleitores é a utilização dos dados das pesquisas de opinião.

A Pesquisa Iuperj-2002 perguntou aos eleitores o que foi mais importante na escolha de deputado federal, o candidato ou o partido ao qual ele pertencia (a possibilidade de dizer ambos foi assinalada, mas não fazia parte da pergunta). O resultado revela que um número expressivo de eleitores (92\%) respondeu que o candidato foi mais importante; apenas $4 \%$ consideraram o partido, e $4 \%$ responderam que ambos eram importantes (ver Tabela 3). Uma outra pergunta solicitou aos eleitores que a pontassem o partido no qual votaram nas eleições para deputado federal. Apenas quatro partidos (PT, PSDB, PMDB e PFL) receberam um número de menções superiores a $2 \%$. Usando o mesmo critério, é possível dizer que o contingente de eleitores "centrados no candidato" variou entre $83 \%$ (PT) e $96 \%$ (PFL). Outro aspecto que reforça o peso reduzido da reputação partidária é o fato de que apenas dois meses depois da eleição $46 \%$ dos eleitores já não se lembraram ou não souberam dizer o nome do partido no qual votaram ${ }^{25}$.

Tabela 3

Na Escolha para Deputado Federal, o que Foi Mais Importante, o Candidato ou o Partido ao qual Ele Pertence

\begin{tabular}{l|c|c|c|c|c}
\hline & $\begin{array}{c}\% \\
\text { Candidato }\end{array}$ & $\begin{array}{c}\% \\
\text { Partido }\end{array}$ & $\begin{array}{c}\% \\
\text { Os Dois }\end{array}$ & $\begin{array}{c}\% \\
\text { Total }\end{array}$ & $\begin{array}{c}\% \\
\text { Total da } \\
\text { Coluna }\end{array}$ \\
\hline PFL & 96 & 2 & 2 & 100 & 4 \\
PMDB & 86 & 8 & 6 & 100 & 8 \\
PSDB & 87 & 7 & 6 & 100 & $\mathbf{1 0}$ \\
PT & 83 & 7 & 10 & 100 & $\mathbf{2 5}$ \\
Outros & 91 & 6 & 3 & 100 & 7 \\
Não sabe/não respondeu & 98 & 1 & 1 & 100 & $\mathbf{4 6}$ \\
\hline Total & 92 & 4 & 4 & 100 & $\mathbf{1 0 0}$ \\
\hline
\end{tabular}

Fonte: Pesquisa Iuperj-2002.

Obs.: $\mathrm{n}=1.394$; chi-quadrado: 79.275 ; sig. $(0,00)$; phi: 0,238 , sig. $<0,001$.

Os dados da Tabela 3 são uma forte evidência da reduzida importância dos partidos na decisão dos eleitores nas eleições para a Câmara dos Deputados. O resultado confirma a previsão dos estudiosos: regras institucionais que estimulam as campanhas centradas em candidatos 
(e não nos partidos) têm como resposta o alto peso da reputação pessoal (e baixo peso da reputação partidária) na escolha do eleitor.

\section{EFEITOS SOBRE A RELAÇÃO DOS DEPUTADOS COM AS BASES ELEITORAIS}

Muitos fatores determinam o tipo de relação que os deputados desenvolvem com os eleitores durante o mandato, sobretudo se esses são mais ou menos inclinados a prestar algum tipo de atendimento particular aos eleitores: a distribuição de poder no interior do Legislativo; a natureza dos partidos; a possibilidade de transferência de recursos do orçamento para as circunscrições dos representantes; o processo de seleção de candidatos pelos partidos; as atribuições das unidades subnacionais. Mas muitos estudos têm enfatizado a importância particular dos estímulos produzidos pelos diferentes sistemas eleitorais (Bogdanor, 1985; Cain, Farejohn e Fiorina, 1987; Cox e McCubbins, 2001; Gallaguer, 2005; Shugart, 2005). Na síntese feita por Gallaguer (2005), uma premissa presente em boa parte dos estudos é que, nos sistemas proporcionais centrados no candidato (STV e lista aberta), o deputado tem incentivos para desenvolver atividades que o diferencie dos seus colegas, sobretudo por meio de atendimento de demandas específicas (idem:562). Mas os estudos dão um passo além e acreditam que essa relação será feita com base em atendimento a interesses particularistas, em geral mobilizando projetos clientelísticos ou provendo ações em defesa dos interesses da circunscrição eleitoral (Cox e McCubbins, 2001; Shugart, 2005). Não existe uma relação necessária entre a lista aberta e o desenvolvimento de atividade parlamentar exclusivamente associada a atender demandas dos eleitores. Um deputado pode, por exemplo, investir esforços na vida legislativa (trabalho em comissões, liderança parlamentar, apresentação de projetos) e no reforço da reputação partidária (liderança da bancada, atividade de direção partidária). Nesse caso, é fundamental que ele tenha algum canal de exposição de sua atividade para os eleitores, seja por intermédio da cobertura da mídia nacional (ou regional), ou por canais próprios que ele desenvolveu (reuniões com correligionários, distribuição de material impresso e, mais recentemente, via internet). Somente estudos empíricos podem mostrar os reais mecanismos que os representantes desenvolvem para cultivar sua reputação junto aos eleitores em cada país.

No Brasil, os deputados federais desenvolvem diferentes padrões de prestação de contas, associados a uma série de fatores, tais como a sua 
base eleitoral, o tipo de ambição de carreira, a especialização parlamentar e o vínculo com determinados grupos de interesse. Um deputado com uma trajetória orientada para defesa de certas políticas (especialista em temas específicos ou representante de determinados grupos de interesse) ou que pertença à elite parlamentar pode conseguir espaço na mídia nacional para cobertura de sua atividade e prescindir de realizar ações particularistas para os seus redutos eleitorais. Por outro lado, parlamentares que não fazem parte da elite parlamentar e/ou foram eleitos com votações hiperconcentradas tendem a privilegiar ações que beneficiem diretamente o seu reduto eleitoral (alocação de emendas do orçamento para a região, intermediação dos prefeitos com o governo federal para provisão de obras e recursos para a região). Ainda sabemos muito pouco sobre como os diferentes padrões de carreira e recursos políticos de cada deputado condicionam o padrão de prestação de contas pós-eleitoral (Carvalho, 2003).

$\mathrm{Na}$ pesquisa que realizou junto aos deputados federais, Carvalho (2000) solicitou que classificassem 17 itens, segundo a importância para o sucesso eleitoral, em uma escala de 10 pontos. Ainda que o objetivo das perguntas não fosse exclusivamente o de traçar um painel do tipo de prestação de contas que os deputados desenvolvem no mandato, as respostas apresentam alguns resultados interessantes. Para efeitos de apresentação dos dados, os resultados foram agregados em cinco grupos: 1) ação junto aos municípios-eleitores; 2) atividade na Câmara dos Deputados; 3) presença na mídia; 4) patronagem; 5) outros. Os valores medianos das respostas para o conjunto dos deputados pesquisados (para os membros dos quatro maiores partidos) são apresentados na Tabela 4.

O primeiro dado que salta aos olhos é a importância central da conexão com a vida municipal. A visita freqüente aos municípios onde o deputado foi bem votado aparece no topo como a atividade de maior importância para o conjunto de deputados e para todos os partidos. A seguir, aparece a liberação de emendas do orçamento e a intermediação do pleito dos prefeitos e lideranças locais. É interessante observar que essas duas últimas atividades não foram julgadas importantes pelos parlamentares do PT. A dúvida é se essas respostas derivaram da natureza mais orientada para políticas específicas (policy-oriented) do partido ou do fato de ele se encontrar na oposição à época em que a pesquisa foi realizada (1999), tendo, assim, limitado acesso aos recursos para a intermediação junto às prefeituras. Os itens associados à atividade na Câ- 
Tabela 4

Em uma Escala de 1 (Menos Importante) a 10 (Muito Importante), Qual a Importância dessas Atividades, para o seu Sucesso Eleitoral? (Valores Medianos, Totais e dos Principais Partidos)

1. Ação Junto aos Municípios-Eleitores

Visita freqüente aos municípios em que foi votado

Obtenção de recursos para os municípios

Encaminhamento de demandas dos prefeitos ou lideranças locais

Atendimento de pedido dos eleitores

2. Atividade na Câmara dos Deputados

Atividade legislativa, em particular a maneira como vota

Posições de destaque no Congresso

Prestígio no Congresso

Projetos de lei apresentados

\section{Presença na Mídia}

Presença na mídia estadual

Presença na mídia nacional

\section{Patronagem}

Nomeação de correligionários para postos na burocracia estadual

Nomeação de correligionários para postos na burocracia municipal

Nomeação de correligionários para postos na burocracia federal

\section{Outros}

Defesa de princípios ideológicos

Organização do partido

Apoio do governador do estado

Apoio de interesses econômicos

\begin{tabular}{|c|c|c|c|c|}
\hline Total & PSDB & PT & PMDB & PFL \\
\hline 9,0 & 9,0 & 9,0 & 9,0 & 9,0 \\
\hline 8,0 & 8,0 & 3,0 & 8,5 & 8,0 \\
\hline 7,0 & 8,0 & 3,0 & 8,0 & 8,0 \\
\hline 5,0 & 5,0 & 2,0 & 6,0 & 6,0 \\
\hline 7,0 & 6,0 & 8,0 & 7,0 & 7,0 \\
\hline 6,0 & 7,0 & 5,0 & 7,0 & 6,0 \\
\hline 6,0 & 5,5 & 5,0 & 6,5 & 6,0 \\
\hline 6,0 & 5,0 & 7,0 & 6,0 & 5,0 \\
\hline 7,0 & 7,0 & 6,5 & 8,0 & 7,0 \\
\hline 5,0 & 4,0 & 5,0 & 4,0 & 5,0 \\
\hline 1,0 & 1,0 & 1,0 & 1,0 & 1,0 \\
\hline 1,0 & 1,0 & 1,0 & 1,0 & 1,0 \\
\hline 1,0 & 1,0 & 1,0 & 1,0 & 1,0 \\
\hline 7,0 & 7,0 & 9,0 & 6,0 & 5,0 \\
\hline 6,0 & 6,0 & 8,0 & 7,0 & 6,0 \\
\hline 3,0 & 5,0 & 1,0 & 1,5 & 5,0 \\
\hline 3,0 & 3,0 & 1,0 & 3,0 & 3,0 \\
\hline
\end{tabular}

Fonte dos dados brutos: Banco de dados da pesquisa Perfil da Câmara dos Deputados - 1999. 
mara dos Deputados receberam valores intermediários. Vale ressaltar o peso reduzido das atividades de liderança e prestígio na Câmara dos Deputados no sucesso eleitoral. Os dados ainda ajudam a desfazer dois mitos sobre a ação parlamentar no Brasil. Os valores insignificantes para a patronagem (nomeação de correligionários nas três esferas de poder) assinalam que esse recurso pode estar sendo utilizado marginalmente como estratégia política no Brasil. Por fim, também é surpreendente o baixo valor atribuído à conexão com o governador para o sucesso eleitoral, talvez um indicador da declinante influência deste sobre as bancadas estaduais.

Mas quais seriam as razões da predominância de um tipo de prestação de contas eminentemente geográfico? Já durante a campanha eleitoral os candidatos escolhem diferentes estratégias de concentração ou dispersão de seus recursos pelo território. A decisão de onde concentrar a campanha (se em um, poucos ou muitos municípios) está, em geral, associada ao perfil político e à disponibilidade de recursos. Uma liderança com fortes vínculos com um determinado município (vereador ou ex-prefeito de uma cidade), por exemplo, provavelmente tenderá a concentrar sua campanha em uma área circunscrita do estado. Por outro lado, uma liderança com trajetória política mais abrangente (secretários de estado, parlamentares com visibilidade na mídia estadual, lideranças de grupos não concentrados geograficamente) pode dispersar seus recursos de campanha por diversas áreas do estado.

Existe uma longa tradição de estudos que investigaram o padrão geográfico da votação dos deputados federais no Brasil (Carvalho, 2003). O propósito é, em geral, distinguir parlamentares que tiveram votações concentradas daqueles com votação dispersa pelo estado, tomando o município como unidade de análise. Mas, em geral, esses estudos têm dois problemas. O primeiro é a concentração da análise apenas nos candidatos eleitos, o que restringe a possibilidade de fazer generalizações. Um mapeamento completo dos padrões de disputa deve incluir também os candidatos derrotados. O segundo é uma associação direta entre os efeitos da competição (concentração e dispersão do voto) e a intenção dos candidatos, esquecendo que o resultado das urnas é o efeito agregado, e muitas vezes não-antecipado, da estratégia de diversos candidatos. Se, por exemplo, muitos candidatos resolvem concentrar a campanha em uma determinada região, o resultado final pode, ao contrário, ser uma grande dispersão da votação naquela região. Para um deputado, o conhecimento das áreas onde recebeu votos (reduto elei- 
toral) é fundamental, pois estas áreas provavelmente serão prioritárias para a sua atividade parlamentar ${ }^{26}$. Ainda que a atividade parlamentar também possa levar em conta a dimensão prospectiva (o deputado poderia priorizar as áreas do estado sem representantes na Câmara e áreas que possam lhe garantir apoio eleitoral no futuro), os indícios são de que a dimensão retrospectiva seja a predominante: o deputado tende a priorizar a atuação em áreas onde recebeu expressiva votação ${ }^{27}$.

Os dados da pesquisa de Carvalho (2000) fornecem pistas muito interessantes para futuras investigações sobre como os deputados se relacionam com os eleitores e quais são as atividades prioritárias da atividade parlamentar no Brasil. Mas os resultados são contundentes com relação à importância da conexão com a vida política municipal. Os municípios precisam ser visitados freqüentemente; o deputado deve se empenhar em obter recursos do orçamento para determinadas áreas e encaminhar o pleito dos prefeitos e lideranças locais.

\section{PUNIR E RECOMPENSAR OS DEPUTADOS NO BRASIL ${ }^{28}$}

O processo pelo qual os eleitores controlam por intermédio do voto seus representantes é um tema caro à teoria democrática (Schumpeter, 1984; Dahl, 1989; Katz, 1997; Powell Jr., 2000; Moreno, Crisp e Shugart, 2003). Na versão tradicional - chamada por Powell Jr. (2000) de accountability model-, as eleições seriam um momento privilegiado para punir ou recompensar os representantes: bons governantes seriam reconduzidos ao poder, enquanto os com desempenho ruim seriam afastados. Na mesma chave, outros autores sugeriram que a relação entre representantes e representados deveria ser pensada a partir do modelo mandante-mandatário (principal-agent-model) (Strom, 2000). Segundo Moreno, Crisp e Shugart,

\footnotetext{
“Dessa perspectiva, o processo decisório em grandes entidades, tais como estados democráticos, implica delegação de autoridade. Em relações deste tipo, o direito de tomar uma decisão é estabelecido pelo mandante para um mandatário, mas esta delegação é condicional. O que significa que ela continua apenas quando é do agrado do mandante. Que essa possa ser interrompida é a essência da accountability. Apenas quando o direito de tomar uma decisão é submetido à possibilidade de interrupção por parte do mandante, uma relação fundada na accountability tem lugar" (2003:83, tradução do autor).
} 
Portanto, o modelo de acccountability seria baseado em um elemento retrospectivo, de avaliação dos que já estão no poder. O eleitor, após avaliar o desempenho de um candidato (ou partido) que esteja em um determinado cargo eletivo, pode recompensá-lo ou puni-lo na eleição seguinte. A recompensa acontece quando o eleitor avalia o representante de maneira positiva e vota por sua reeleição (ou de seu partido). A punição ocorre quando o eleitor escolhe outro candidato (ou partido) ou prefere não expressar preferência por nenhum candidato (não comparecimento ou anulação do voto).

Vale a pena explorar em que medida o sistema representativo brasileiro oferece aos eleitores mecanismos claros para controlar eleitoralmente os seus representantes. Uma primeira versão de voto retrospectivo pressupõe três passos: 1) que o eleitor se lembre em quem votou; 2) que o candidato seja eleito; 3) que o eleitor acompanhe a atividade do representante. A ausência de pesquisas sobre o contingente de eleitores que acompanham a atuação dos deputados federais no Brasil impede que se possa fazer qualquer avaliação do terceiro passo. Mas temos algumas evidências para avaliar os outros dois aspectos. O Estudo Eleitoral Brasileiro - Eseb, realizado em 2002, fez uma série de perguntas sobre a memória do eleitor ${ }^{29}$. Perguntados se lembravam em quem haviam votado para deputado federal na eleição anterior (1998), 67\% disseram que não se lembravam, e apenas 15\% apontaram um nome de um candidato que de fato concorreu naquele ano (ver Tabela 5). Se retirarmos da listagem de candidatos lembrados aqueles que se elegeram, esse número ficaria ainda mais reduzido. Portanto, podemos dizer que o uso do voto retrospectivo nas eleições para a Câmara dos Deputados (em 2002) foi completamente marginal.

Alternativamente, é possível pensar uma modalidade de voto retrospectivo que desconsiderasse a memória do voto na eleição antecedente. Nesse caso, o eleitor poderia simplesmente decidir votar em um deputado que tenha chamado a sua atenção positivamente durante a legislatura ou simplesmente eliminar das suas escolhas os nomes que possam ter se destacado negativamente ${ }^{30}$. Nessa opção, o eleitor não precisaria lembrar em quem votou, mas conhecer um deputado em atividade. Aqui também os resultados do Eseb podem ajudar. Os eleitores foram perguntados se conheciam algum deputado federal do estado. Ainda que a pesquisa tenha sido realizada logo após a campanha (com alta exposição dos deputados), 59\% não se lembravam ou não souberam responder; $16 \%$ apresentaram nomes incorretos e inexisten- 
Tabela 5

Memória do Voto. Conjunto de Perguntas feitas pelo

Eseb, 2002

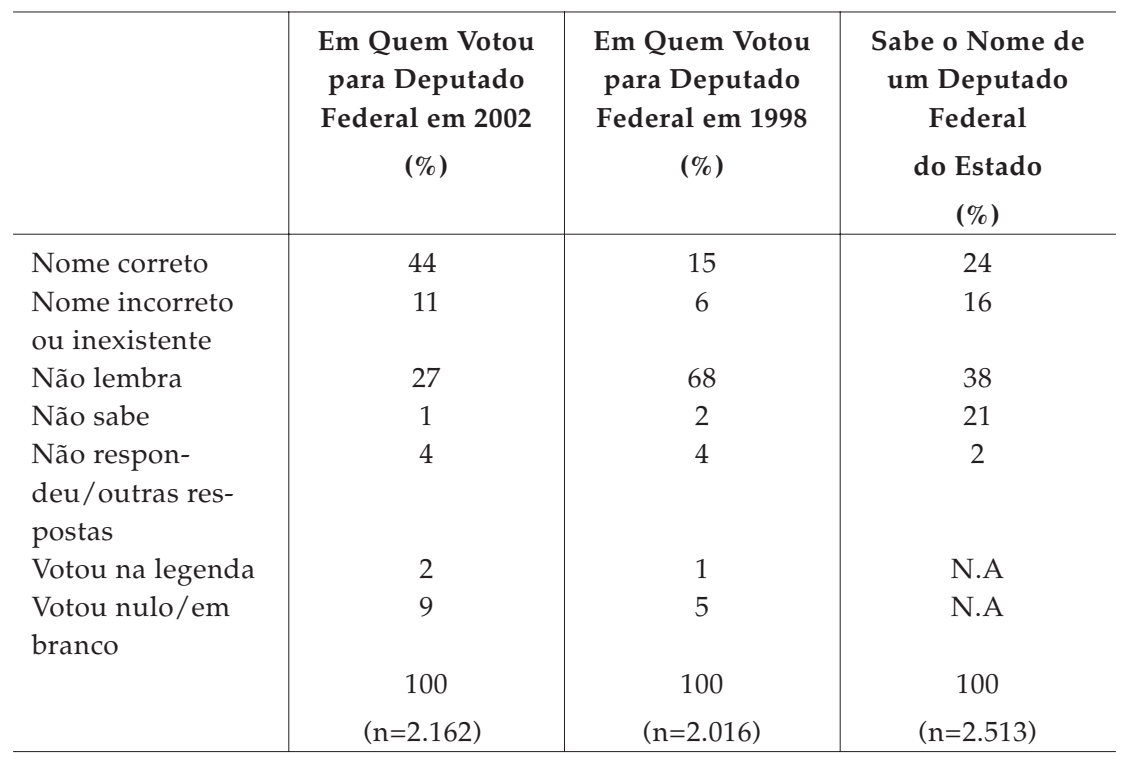

Fonte: Banco de dados do Eseb (2002).

tes; apenas $24 \%$ apresentaram o nome correto de algum deputado federal do estado. Mesmo com a opção (implausível) de que todos os eleitores que sabem o nome de um deputado tenham votado retrospectivamente, o contingente ainda seria reduzido.

Os dados do Eseb sugerem que um número reduzido de eleitores tem condições de fazer uma avaliação retrospectiva da atuação do mandato de um deputado. Minha sugestão é que grande parte das escolhas é resultado de estímulos gerados durante a própria campanha eleitoral. Como vimos, as estratégias de campanha derivam em larga medida dos recursos políticos e do padrão de carreira do candidato. Portanto, o voto como resposta à mobilização eleitoral contemplaria um número variado de estratégias. Os candidatos poderiam enfatizar suas virtudes pessoais, ressaltar algum tipo de identidade com o eleitor (territorial, profissional, de gênero, religiosa), apresentar uma campanha orientada para políticas (em defesas de temas e grupos sociais específicos). As campanhas poderiam até mesmo mobilizar a reputação partidária, por exemplo, quando o partido pede para os eleitores votarem especificamente na legenda. Mas o Eseb mostra o peso das estratégias 
de mobilização eleitoral de curto prazo na decisão do voto. Poucas semanas depois das eleições, apenas $46 \%$ (44\% em um nome e $2 \%$ em uma legenda) lembravam em quem tinham votado.

O cruzamento do padrão de escolha (personalizada ou partidária) com o tipo de controle eleitoral (retrospectivo, não-retrospectivo) produz quatro tipos ideais de escolha nas eleições para a Câmara dos Deputados (ver Quadro 1). O primeiro grupo, voto personalizado e retrospectivo, tem limites objetivos para atingir um grande número de eleitores (ausência de memória eleitoral e desconhecimento dos deputados com mandato). Um segundo grupo, voto partidário e retrospectivo, seria composto pelo reduzido número de eleitores que consideram o partido mais importante que o candidato e votam sempre no mesmo partido; este voto é obtido, sobretudo, pelo PT. Um terceiro grupo, voto partidário não-retrospectivo, é composto por eleitores que votam em uma legenda, atendendo o pedido de uma liderança estadual ou candidato a um cargo majoritário. $\mathrm{O}$ último grupo, voto personalizado e não-retrospectivo, seria composto por eleitores que são mobilizados, sobretudo, pelos apelos da campanha, exclusive os apelos dos candidatos com mandato. Minha sugestão é que a grande maioria dos eleitores faz suas escolhas a partir de apelos eleitorais que não estão associados a um julgamento do mandato.

\section{Quadro 1}

Voto Personalizado-Partidário e Retrospectivo-Não-Retrospectivo

\begin{tabular}{|l|l|}
\hline Voto Personalizado e Retrospectivo & Voto Partidário e Retrospectivo \\
$\begin{array}{l}\text { Exemplo: votos em determinados depu- } \\
\text { tados federais com mandato por conta de } \\
\text { seu desempenho na legislatura. }\end{array}$ & $\begin{array}{l}\text { Exemplo: eleitores com identidade parti- } \\
\text { dária de longo prazo, sobretudo, com o } \\
\text { PT. }\end{array}$ \\
\hline $\begin{array}{l}\text { Voto Personalizado e } \\
\text { Não-Retrospectivo }\end{array}$ & $\begin{array}{l}\text { Voto Partidário e Não-Retrospectivo } \\
\text { Exemplo: votos a partir de identidade } \\
\begin{array}{l}\text { com o candidato (territorial, social, gru- } \\
\text { pos de interesse, religião); promessas de de legenda de curto pra- } \\
\text { atuação futura ou atributos pessoais do } \\
\text { candidato. }\end{array}\end{array}$ \\
\hline
\end{tabular}

Fonte: Elaboração do autor.

\section{CONCLUSÃO}

O objetivo do artigo foi apresentar um quadro geral do funcionamento do sistema eleitoral de lista aberta nas eleições para a Câmara dos De- 
putados no Brasil. Para isso, uma série de evidências empíricas foi mobilizada (resultados eleitorais e pesquisas de opinião). Apesar de ser um estudo de caso sobre as diversas dimensões de um sistema eleitoral (lista aberta) em um dado país (Brasil), o texto procurou dialogar com os estudos de corte mais comparativo. Em muitos aspectos há uma confluência com a prática de outras democracias que utilizam o mesmo sistema eleitoral: campanhas centradas no candidato; voto personalizado; estímulo à conexão eleitoral por fora da estrutura partidária. Mas em outros pontos o artigo revelou algumas especificidades da experiência brasileira: a possibilidade do voto de legenda; a alta taxa de derrotas dos candidatos por outros nomes do mesmo partido (possível evidência da competitividade); a importância da conexão com as redes municipais para a atividade parlamentar; a reduzida capacidade de controle eleitoral dos representantes.

Em diversas passagens, foi assinalada a necessidade de fazer mais pesquisas empíricas. Alguns temas, em especial, merecem um tratamento mais cuidadoso: as motivações dos eleitores quando escolhem os seus deputados; o papel das redes de apoio nos municípios na campanha e durante o mandato; o processo de seleção dos candidatos pelos partidos; o perfil dos cidadãos que se candidatam; o papel dos diversos recursos de campanha (horário no rádio e na televisão; gastos; distribuição espacial) sobre o sucesso dos candidatos. Enfim, uma longa pauta para o futuro.

(Recebido para publicação em maio de 2006)

(Versão definitiva em novembro de 2006) 


\section{NOTAS}

1. O eleitorado do Brasil está em http://www.jaironicolau.iuperj.br; o dos outros países em http://www.idea.int.

2. Um problema do artigo de Barry Ames é que a apresentação dos dados impede o leitor de avaliar o peso e a significância das variáveis selecionadas por ele.

3. As pesquisas são: Estudo Eleitoral Brasileiro - Eseb; a Pesquisa Pós-Eleitoral Iuperj-2002; e O Perfil dos Deputados Federais Brasileiros, 1999 (pesquisa coordenada por Nelson Carvalho).

4. Shugart, em sua tipologia sobre sistemas preferenciais, chama o modelo adotado no Chile, na Finlândia e na Polônia de quasi-list; enquanto os casos do Brasil e da Itália (pré-1993) são considerados como open-list (Shugart, 2005:42).

5. A legislação previa uma série de possibilidades de contar o voto no caso de o eleitor votar apenas em um nome (voto contado para o nome e para o partido), ou somente no partido (voto contado para o partido). Nos casos de o eleitor votar em candidatos e legendas diferenciadas, o voto era contado para a legenda. Como as cédulas eram distribuídas pelos partidos, esses erros não eram freqüentes. Ver o artigo 55 do Código Eleitoral Brasileiro de 1950.

6. A urna eletrônica foi introduzida paulatinamente. Em 1996, foi utilizada por 32\% do eleitorado, residente em 57 municípios (capitais de estado e cidades com mais de 200 mil eleitores). Em 1998, foi utilizada por $58 \%$ do eleitorado, residente em 537 municípios (todos os municípios do Rio de Janeiro, Alagoas, Roraima e Amapá; no Distrito Federal; nos municípios com mais de 40.500 eleitores dos outros estados). Nas eleições de 2000 (municipais) e 2002 (gerais), todos os eleitores votaram na urna eletrônica.

7. Para o quadro completo do número de candidaturas por sexo, ver Álvares (2004:236).

8. Nenhum partido, pelo que pude averiguar, deixou de conceder lugar na lista para um dos parlamentares que tentaram a reeleição em 2002.

9. Sobre as coligações eleitorais no Brasil, ver Krause e Schmitt (2005).

10. O único estudo sistemático a respeito do processo de seleção de candidatos no Brasil é o de Álvares (2004). O trabalho é um estudo de caso, com ênfase na escolha das mulheres do Estado do Pará.

11. Dados obtidos junto ao Tribunal Superior Eleitoral - TSE.

12. Não existem estudos sistemáticos sobre como os candidatos organizam suas campanhas no Brasil. Os comentários dessa seção são, em larga medida, derivados da minha experiência em algumas campanhas eleitorais.

13. Apesar das exigências de prestação de contas, a utilização de recursos ilegais para financiar as campanhas é prática comum no Brasil. Prática que foi reconhecida por diversos políticos (inclusive o presidente Luiz Inácio Lula da Silva) durante a Comissão Parlamentar de Inquérito - CPI dos Correios, que investigou o chamado Escândalo do Mensalão (2005-2006). O que sabemos sobre os gastos de campanha são os valores declarados oficialmente pelos candidatos. Embora a validade destes dados seja questionável, eles têm sido utilizados. Ver, por exemplo, Samuels (2002). 
14. A Lei $\mathrm{n}-11.300$, de maio de 2006, proibiu a distribuição de brindes durante as eleições.

15. Alguns estudos sobre as eleições antes de 1945 (Leal, 1986; Graham, 1997; Faoro, 2004) enfatizaram a presença generalizada de práticas clientelistas no processo eleitoral brasileiro. Mas não existem estudos sistemáticos sobre o tema durante a República de 1946 e no atual período democrático.

16. Até 2002, era comum o uso de outdoors, que passou a ser proibido pela Lei n⿳ํㅡㄹ 11.300, de maio de 2006.

17. Os autores não testaram uma hipótese plausível: a associação entre o tempo no horário eleitoral gratuito e a votação na eleição anterior. Os candidatos podem ter recebido mais tempo no HGPE em uma eleição, justamente por terem sido bem votados na eleição anterior. Somente análises multivariadas poderão chegar a conclusões mais precisas a respeito do real efeito da aparição no HGPE sobre o sucesso eleitoral dos candidatos.

18. Em trabalho posterior, Shugart (2005) deu atenção especial aos sistemas de lista com voto preferencial.

19. Figueiredo e Limongi criticam a idéia de que as campanhas para deputado federal sejam concentradas no candidato. Segundo eles "[...] Em um sistema de 'lista aberta', a competição intrapartidária não suplanta a interpartidária. Como os votos na lista são transferidos, qualquer voto dado a um candidato do partido aumenta as chances de os demais se elegerem" (2002:309).

20. Cálculos feitos com os dados da pesquisa Perfil dos Deputados Brasileiros - 1999. Agradeço a gentileza de Nelson Carvalho de ter compartilhado o banco de dados.

21. Minha hipótese, que precisa ser investigada, é que a alta imprevisibilidade da disputa seja uma das causas do alto custo das campanhas eleitorais no Brasil. É interessante observar que mesmo parlamentares com muitos anos de mandato gastam muito nas eleições.

22. Para o Brasil, Figueiredo e Limongi (1996) utilizaram um critério diferente, considerando derrotas na lista aquelas em que o número de eleitos pelo partido é superior ao número de candidatos à reeleição.

23. Aqui considerei apenas os candidatos dos partidos, e não a lista de candidatos de cada coligação.

24. Um exemplo da cédula utilizada em 1990 pode ser encontrado em Nicolau (2004).

25. A mesma pergunta feita em relação ao deputado estadual apresenta resultados semelhantes: $93 \%$ responderam o candidato, $2 \%$, o partido e $4 \%$, ambos.

26. Visão diferente é apresentada por Santos (1999), que sustenta que os deputados brasileiros não têm mecanismos para identificar os seus redutos eleitorais.

27. Os estudiosos do padrão geográfico de voto no Brasil desenvolveram diferentes formas de identificar os redutos eleitorais dos deputados, todas, contudo, baseadas nos resultados das eleições (Ames, 1995; Pereira e Rennó, 2001; Carvalho, 2003).

28. Esta seção desenvolve alguns pontos inicialmente apontados em Nicolau (2002a).

29. A pesquisa foi realizada entre os meses de dezembro de 2002 e fevereiro de 2003.

30. Alguns autores que estudaram a reeleição nas eleições para a Câmara dos Deputados partiram dessa premissa. Ames (1995) sustenta que a capacidade de transferir recursos (por intermédio de aprovação de emendas) para as localidades específicas traz 


\section{Jairo Nicolau}

grandes vantagens eleitorais para os candidatos. Pereira e Rennó (2001) vão mais longe ao analisarem a liberação de emendas orçamentárias. Eles sustentam que as chances de reeleição em 1998, para os deputados eleitos em 1994, estariam associadas à capacidade destes de liberarem, durante o mandato, emendas orçamentárias para as suas bases eleitorais.

\section{REFERÊNCIAS BIBLIOGRÁFICAS}

ÁLVARES, Maria Luzia. (2004), Mulheres na Competição Eleitoral: Seleção de Candidaturas e Padrão de Carreira Política no Brasil. Tese de Doutorado, Iuperj.

AMES, Barry. (1995), "Electoral Strategy under Open-List Proportional Representation". American Journal of Political Science, vol. 39, no 2, pp. 406-433.

BOGDANOR, Vernon. (1985), Representatives of People? Parliamentarians and Constituents in Western Democracies. Aldershot, Gower.

BOWLER, Shaum e GROFMAN, Bernard (eds.). (2000), Elections in Australia, Ireland and Malta under the Single Transferable Vote: Reflections on an Embedded Institution. Ann Arbor, Michigan University Press.

CAIN, Bruce, FAREJOHN, John A. e FIORINA, Morris. (1987), The Personal Vote: Constituency Service and Electoral Independence. Cambridge, Harvard University Press.

CAREY, John M. e SHUGART, Matthew Soberg. (1995), "Incentives to Cultivate a Personal Vote: A Rank Ordering of Electoral Formulas". Electoral Studies, vol. 14, no 4, pp. 417-439.

CARVALHO, Nelson Rojas de. (2000), "Peço a Palavra: Primeiro Nós". InsightInteligência, vol. 9, pp. 89-96.

. (2003), Eno Início Eram as Bases: Geografia Política do Voto e Comportamento Legislativo no Brasil. Rio de Janeiro, Editora Revan.

COX, Gary W. e McCUBBINS, Mathew D. (2001), "The Institutional Determinants of Economic Policy", in S. Haggard e M. D. McCubbins (eds.), Presidents, Parliaments and Policy. Cambridge, Cambridge University Press.

DAHL, Robert. (1989), Um Prefácio à Teoria Democrática. Rio de Janeiro, Jorge Zahar Editor.

DALTON, Russel J. e WATTEMBERG, Martin P. (eds.). (2000), Parties Without Partisans: Political Change in Advanced Ind ustrial Democracies. Oxford, Oxford University Press.

FAORO, Raymundo. (2004), Os Donos do Poder: Formação do Patronato Brasileiro. Porto Alegre, Globo.

FIGUEIREDO, Argelina Cheibub e LIMONGI, Fernando. (1996), “Congresso Nacional: Organização, Processo Legislativo e Produção Legal". Cadernos de Pesquisa, no 5, Cebrap. 
. (2002), “Incentivos Eleitorais, Partidos e Política Orçamentária". Dados, vol. 45, no 2, pp. 303-344.

GALLAGUER, Michael. (2005), “Conclusion”, in M. Gallaguer e P. Mitchell (eds.), The Politics of Electoral Systems. Oxford, Oxford University Press.

e MITCHELL, Paul. (2005), "Introduction", in M. Gallaguer e P. Mitchell (eds.), The Politics of Electoral Systems. Oxford, Oxford University Press.

GRAHAM, Richard. (1997), Clientelismo e Política no Brasil do Século XIX. Rio de Janeiro, Editora UFRJ.

GROFMAN, Bernard, LEE, Sung-Chull, WINKLER, Edwin A. e WOODALL, Brian (eds.). (1999), Elections in Japan, Korea and Taiwan under the Single Non-Transferable Vote. Ann Arbor, University of Michigan Press.

GUNTHER, Richard e DIAMOND, Larry. (2003), “Species of Political Parties: A New Tipology". Party Politics, vol. 9, no 2, pp. 167-199.

KARVONEN, Lauri. (2004), "Preferential Voting: Incidence and Effects". International Political Science Review, vol. 25, no 2, pp. 203-226.

KATZ, Richard S. (1986), "Intraparty Preference Voting", in B. Grofman e A. Lijphart (eds.), Electoral Laws and Their Political Consequences. New York, Agathon Press.

_. (1997), Democracy and Elections. Oxford, Oxford University Press.

. (2005), “Why are There so Many (or so Few) Electoral Reforms?", in M. Gallaguer e P. Mitchell (eds.), The Politics of Electoral Systems. Oxford, Oxford University Press.

KRAUSE, Silvana e SCHMITT, Rogério. (2005), Partidos e Coligações no Brasil. São Paulo, Editora Unesp/Konrad Adenauer.

LEAL, Paulo Roberto Figueira. (2005), O PT e o Dilema da Representação Política. Rio de Janeiro, Fundação Getulio Vargas Editora.

LEAL, Victor Nunes. (1986), Coronelismo, Enxada e Voto. São Paulo, Editora Alfa-Ômega.

MAINWARING, Scott. (1991), "Politicians, Parties, and Electoral Systems: Brazil in Comparative Perspective". Comparative Politics, vol. 24, no 1, pp. 21-43.

MORENO, Erika, CRISP, Brian F. e SHUGART, Matthew Soberg. (2003), “Accountability Defict in Latin America", in S. Mainwaring e C. Welna (eds.), Democratic Accountability in Latin America. Oxford, Oxford University Press.

NICOLAU, Jairo. (1996), Multipartidarismo e Democracia: Um Estudo sobre o Sistema Partidário Brasileiro (1985-94). Rio de Janeiro, Fundação Getulio Vargas Editora.

. (2002), História do Voto no Brasil. Rio de Janeiro, Jorge Zahar.

. (2002a), “Como Controlar o Representante? Considerações sobre as Eleições para

a Câmara dos Deputados no Brasil”. Dados, vol. 45, no 2, pp. 219-236.

. (2004), Sistemas Eleitorais. Rio de Janeiro, Fundação Getulio Vargas Editora.

NORRIS, Pippa. (2004), Electoral Engineering: Voting Rules and Political Behavior. Cambridge, Cambridge University Press. 


\section{Jairo Nicolau}

PEREIRA, Carlos e RENNÓ, Lúcio. (2001), “O que É que o Reeleito Tem? Dinâmicas Político-Institucionais Locais e Nacionais nas Eleições de 1998 para a Câmara dos Deputados". Dados, vol. 44, no 2, pp. 323-362.

PORTO, Walter Costa. (1989), O Voto no Brasil: Da Colônia à Quinta República. Brasília, Senado Federal.

POWELL JR., Bingham G. (2000), Elections as Instruments of Democracy: Majoritarian and Proportional Visions. New Haven, Yale University Press.

RAUNIO, Tapio. (2005), “Finland: One Hundred Years of Quietude”, in M. Gallaguer e P. Mitchell (eds.), The Politics of Electoral Systems. Oxford, Oxford University Press.

SAMUELS, David. (1999), "Incentives to Cultivate a Party Vote in a Candidate-Centric Electoral System". Comparative Political Studies, vol. 32, no 4.

. (2002), "Pork-Barrel Politics is Not Credit-Claiming or Advertising: Campaign Finance and the Sources of the Personal Vote in Brazil". Journal of Politics, vol. 64, no3, pp. 845-863.

SANTOS, Fabiano. (1999), “Instituições Eleitorais e Desempenho do Presidencialismo no Brasil”. Dados, vol. 42, no 1, pp. 111-138.

SCHMITT, Rogério, CARNEIRO, Leandro P. e KUSCHNIR, Karina. (1999), “Estratégias de Campanha no Horário Gratuito de Propaganda Eleitoral em Eleições Proporcionais". Dados, vol. 42, no 2, pp. 277-301.

SCHUMPETER, Joseph. (1984), Capitalismo, Socialismo, Democracia. Rio de Janeiro, Jorge Zahar Editor.

SHUGART, Matthew Soberg. (2005), "Comparative Electoral Systems Research: The Maturation of a Field and a New Challenge Ahead", in M. Gallaguer e P. Mitchell (eds.), The Politics of Electoral Systems. Oxford, Oxford University Press.

SIAVELES, Peter M. (2005), "Chile: The Unexpected (and Expected) Consequences of Electoral Engineering", in M. Gallaguer e P. Mitchell (eds.), The Politics of Electoral Systems. Oxford, Oxford University Press.

STROM, Kaare. (2000), “Delegation and Accountability in Parliamentary Democracies”. European Journal of Political Research, vol. 37, no 3, pp. 261-289. 


\section{LISTA DE SIGLAS}

PC do B - Partido Comunista do Brasil

PDT - Partido Democrático Trabalhista

PFL - Partido da Frente Liberal

PL - Partido Liberal

PMDB - Partido do Movimento Democrático Brasileiro

PP - Partido Progressista

PPB - Partido Progressista Brasileiro

PPS - Partido Popular Socialista

PSB - Partido Socialista Brasileiro

PSDB - Partido da Social Democracia Brasileira

PT - Partido dos Trabalhadores

PTB - Partido Trabalhista Brasileiro

\section{ABSTRACT}

The Open-List of Electoral System in Brazil

This article analyzes the open-list electoral system in Brazil in the elections for the Chamber of Deputies (Lower House) and compares it to other countries that employ this mechanism. The author describes the history and functioning of the prevailing electoral system; evaluates the list's impact on parties, voters, and the relationship between Deputies and their constituencies; and discusses the mechanisms offered by the electoral system for voters to either punish or reward their representatives. Linking the Brazilian case to current analyses of electoral systems, the article draws on evidence from three studies conducted with members of the Brazilian Congress and voters.

Key words: electoral system; open-lists; Chamber of Deputies 


\section{RÉSUMÉ}

Le Système Électoral de Liste Ouverte au Brésil

Dans cet article, on examine le système brésilien de liste ouverte pour la Chambre des Députés, en le comparant à d'autres pays qui se servent de ce même mécanisme. On décrit l'histoire et le fonctionnement du système électoral actuel; on évalue l'impact de cette liste sur les partis, les électeurs et la relation des députés avec leurs bases électorales; on discute les moyens que le système électoral offre aux électeurs pour punir ou récompenser leurs représentants. En cherchant à comparer le cas brésilien aux réflexions courantes sur les systèmes électoraux, on se sert d'évidences présentées dans trois recherches effectuées auprès de parlementaires et électeurs.

Mots-clé: système électoral; liste ouverte; Chambre des Députés 